\title{
Sentidos do trabalho e do afastamento por problemas de saúde mental para motoristas de transporte coletivo urbano: um estudo de caso
}

\author{
Júlia Gonçalves e Caroline Stumpf Buaes \\ Centro Universitário Franciscano, UNIFRA (Santa Maria, RS)
}

\begin{abstract}
Os desequilíbrios entre condições de trabalho, a organização do trabalho e a expectativa do trabalhador provocam o adoecimento e a impossibilidade de continuar exercendo sua função. Este artigo buscou entender os sentidos do trabalho e do afastamento por problemas de saúde mental produzidos por motoristas de transporte coletivo urbano. Para tanto foi realizado um estudo de caso em uma empresa no Estado do Rio Grande do Sul. Os resultados apontam para o caráter polifônico das narrativas dos trabalhadores. O trabalho de motorista é associado à realização de um sonho, ao sustento e ao status conferido por ser motorista dessa empresa. A forte vinculação com o trabalho e com a empresa, assim como o sentimento gerado pelo olhar discriminatório do outro, potencializam o sofrimento vivido durante o afastamento. Nesse sentido, sinaliza-se a importância da criação de espaços na organização que promovam escuta, acolhimento, a qualidade de vida no trabalho e a circulação de discursos de saúde e bem-estar.
\end{abstract}

Palavras-chave: Sentido, Trabalho, Afastamento, Saúde do trabalhador.

Sense of work and the removal to drivers of public transport: a case study

The unbalance between the work conditions, work organization and the expectations of the worker provoke a sickening and the impossibility of continuing exercising the job. This article aimed at understanding the work senses and the leave for a mental health disease produced by urban mass transportation conductors. For that, a case study was carried out in a company in the state of Rio Grande do Sul. The results point at the polyphonic character of the speech of the workers. The job of the conductor is associated to the achievement of a dream, the living and the status given for being the conductor of the company. The strong binding with the job and with the company as well as the feeling generated by the discriminating look of the other potentiates the suffering experienced during the leave. In this sense, the importance of the creation of spaces in the organization is signaled in which promotes the hearing, the welcoming and health and well-being speech circulation.

Keywords: Sense, Job, Leave, Worker health.

O trabalho marca fortemente a existência humana com seus diferentes significados, sentidos e lugares ao longo da história. Atualmente, os temas Saúde do Trabalhador e Qualidade de Vida no Trabalho vêm sendo focos de discussão em diferentes campos do conhecimento. Cada vez mais as empresas buscam processos de trabalho mais humanizados, procuram proporcionar um ambiente mais equilibrado, em que os danos à saúde do trabalhador sejam reduzidos, e que leve em conta ambos os lados, o trabalhador e a empresa. Isto é, ao gerar maior satisfação de seus trabalhadores, incrementará a produtividade e, consequentemente, os lucros da organização. Esses conceitos de qualidade de vida no trabalho buscam superar os danos causados pelo trabalho, visando à prevenção e à neutralização dos acidentes e doenças tidos como relacionados ao trabalho.

As condições de trabalho interferem nos estados psíquico, físico e biológico do trabalhador, e quando não são adequadas se traduzem em uma série de problemas de saúde física e mental. Quando falamos em transporte coletivo urbano, referimo-nos a um serviço que atende a boa parte da população. Assim, sua qualidade reflete na melhoria de vida da população urbana, que utiliza diretamente esse serviço ou que, de alguma maneira, sofre suas interferências. 
As repercussões do processo de trabalho sobre a saúde do trabalhador são derivadas tanto das condições de trabalho como de sua organização. As condições de trabalho que influenciam o bem-estar do trabalhador incluem a percepção das tarefas, das relações sociais de trabalho, da hierarquia, do controle e do sentido que o trabalho toma para o trabalhador, da carga real ou sentida, das condições físicas e ergonômicas do ambiente, entre outras. Quando ocorrem desequilíbrios entre as condições de trabalho, a organização do trabalho e a expectativa do trabalhador, deparamo-nos com o adoecimento e a impossibilidade de continuar exercendo a função. E, assim, se dá o afastamento do trabalhador de seu trabalho.

Tendo em vista as relações entre os contextos de trabalho e a saúde do trabalhador, realizou-se um estudo, como Trabalho Final de Graduação em Psicologia, em uma empresa de transporte coletivo urbano do Estado do Rio Grande do Sul, buscando entender os sentidos do trabalho e do afastamento por doença mental produzidos por trabalhadores. Para tanto foram realizadas observações nos terminais da empresa e em reuniões, realizadas pela psicóloga da empresa, com os afastados, além de uma análise estatística de documentos da empresa referentes aos afastamentos, que objetivou levantar um perfil dos afastados. Inicialmente foi realizada uma busca na lista dos nomes dos colaboradores que estavam afastados da empresa, a partir da qual foram vistas as pastas de cada colaborador, as quais continham dados pessoais, atestados apresentados e um pequeno histórico dos anos de trabalho na empresa. Após essa etapa inicial, foram realizadas entrevistas com três colaboradores afastados com o intuito de compreender os sentidos atribuídos às suas experiências no trabalho e no afastamento.

\section{Contextualização do local de pesquisa}

A pesquisa foi realizada em uma empresa de transporte coletivo urbano que possui cerca de 520 colaboradores e atende $63 \%$ de todo o transporte coletivo do município em que está localizada, no Rio Grande do Sul. Esta pesquisa realizada entre os meses de julho e outubro de 2009 foi apresentada como trabalho de conclusão de curso de graduação em Psicologia. O interesse pela temática saúde do trabalhador surgiu a partir da experiência de estágio curricular realizado na empresa, onde se percebeu um número elevado de afastamentos de trabalhadores por problemas de doença mental. Essa empresa caracteriza-se como familiar, em que os membros da família exercem considerável controle administrativo, possuindo uma parcela expressiva do capital. Assim, existe estreita ou considerável relação entre propriedade e controle, sendo o controle exercido justamente com base na propriedade (Lanzana \& Constanzi, 1999).

A partir das observações e conhecimento adquirido com o estágio realizado antes da pesquisa na empresa, pôde-se perceber que a organização apresenta características explícitas da estrutura de uma empresa familiar. Qualidades como lealdade, confiança e o trabalhar "vestindo a camisa" da empresa são valorizadas no contexto organizacional, sendo utilizadas, muitas vezes, como critérios para promoções. A empresa ainda oferece relativa estabilidade de emprego, pois há uma espécie de "camaradismo" entre diretoria, gerentes e colaboradores, em que os critérios de antiguidade, de disponibilidade para o trabalho, de interesse e de empenho para com as coisas da empresa são valorizados e de certa forma beneficiários em pedidos de folgas e trocas de horários. Além disso, os diretores são sensíveis social e politicamente em relação aos seus trabalhadores, estando sempre por perto e dispostos a escutá-los, promovendo reuniões apenas com o intuído de ouvir seus colaboradores.

Há uma preocupação em manter uma continuidade na administração - mesmo durante o processo sucessório - através de treinamento dos próximos sucessores, procurando o fortalecimento de um elo entre o passado, o presente e o futuro. Ser uma empresa familiar 
preocupada em manter a continuidade da administração produz, por um lado, elementos favoráveis para o bom desenvolvimento da empresa como para a criação de um ambiente mais saudável para os trabalhadores. Mas, por outro, representa desvantagens em relação a outras organizações, que visam mais especificamente à produção, ao crescimento e ao lucro, que, segundo Lodi (1993), interferem nos resultados da empresa. Apesar de a diretoria compreender a interferência desses aspectos nos resultados da empresa, parece muitas vezes que não há disposição comportamental para modificá-las, uma vez que, para isso, deveria haver mudança em nível de cultura organizacional.

A empresa recebe uma consultoria prestada pela mesma psicóloga há cerca de dezenove anos. As atividades desenvolvidas envolvem seleção de funcionários, treinamentos, capacitações, grupos, entre outras. Além disso, cria, organiza e desenvolve programas que visem ao bem-estar, à qualidade e à saúde do trabalhador com a finalidade de amenizar algumas das consequências maléficas do trabalho, como, por exemplo, a pressão pelo desempenho, para atingir metas, o estresse, o trabalho com o público e com o trânsito.

\section{Método de pesquisa e análise}

A pesquisa trata de um estudo de caso (Gil, 2007), composto por duas etapas interdependentes que foi submetido e aprovado pelo Comitê de Ética do Centro Universitário Franciscano. A primeira etapa foi realizada através de um estudo quantitativo, de caráter exploratório, em que se buscou levantar um perfil dos colaboradores - motoristas e cobradores - que entraram em afastamento por "doenças do sistema nervoso"1. O levantamento do perfil dos trabalhadores que entram em afastamento foi produzido por meio da análise de tabelas de controle de afastamentos mensais da empresa dos meses de janeiro a julho de 2009. Os dados apontaram um número de 23 colaboradores com 38 pedidos de afastamento.

Realizou-se, então, uma análise estatística descritiva, constatando que o perfil dos afastados é de motoristas (56,5\%), com idade entre 26 e 35 anos (34,8\%), casados (56,5\%), com ensino fundamental completo $(47,8 \%)$ e com tempo médio de trabalho na empresa de 6 a 10 anos (39,2\%). A maior frequência de número de dias de afastamento foi de 1 (um) dia $(60,9 \%)$ e evidenciou-se que $69,6 \%$ dos colaboradores que se afastaram por "doenças do sistema nervoso" também se afastaram por outros motivos no mesmo período analisado. Dos 23 colaboradores que solicitaram o afastamento, $73,9 \%$ retornaram ao trabalho e no momento estão exercendo suas funções, enquanto $27,1 \%$ estão afastados pelo Instituto Nacional do Seguridade Social (INSS).

O perfil do afastamento demonstrou ainda que, dos 38 pedidos de afastamento por "doenças do sistema nervoso, em 34,8\% foi solicitado apenas um dia de afastamento e em $43,5 \%$ foi na terça-feira. Além disso, o mês em que ficou evidente o maior número de afastamentos foi o mês de maio.

Também foram realizadas observações do ambiente e das relações de trabalho que permitiram conhecer o ambiente e as condições de trabalho, assim como as relações estabelecidas entre os colaboradores. Essas observações foram registradas em diário de campo (Wikin, 1998).

A coleta dos dados estáticos possibilitou conhecer o panorama da situação de afastamentos dos trabalhadores por adoecimento no contexto organizacional em que a pesquisa foi realizada. Nesse sentido, eles serviram como uma fase exploratória da problemática analisada qualitativamente na segunda fase do estudo.

1 Terminologia utilizada pela empresa para se referir às doenças de saúde mental. 
O segundo momento da pesquisa, de cunho qualitativo (Minayo, 2002), procurou compreender os sentidos que o colaborador atribui à vivência do trabalho e a experiência do afastamento. Participaram dessa etapa da pesquisa três trabalhadores que possuem características muito próximas ao perfil levantado anteriormente e que entraram em afastamento durante o período de janeiro a julho de 2009. Todos são motoristas, com idade entre 35 e 40 anos, tendo trabalhado entre 3 e 16 anos na empresa. Dois dos participantes encontravam-se ainda em afastamento no período da coleta de dados do estudo, enquanto um já havia retornado ao trabalho.

Para a geração de dados foram realizadas entrevistas semiestruturadas (Gil, 2007) individuais com três colaboradores, as quais foram formuladas com perguntas abertas, permitindo a espontaneidade na fala do participante, mas sem deixar de priorizar a investigação dos sentidos do trabalho e afastamento para os participantes.

A análise dos dados coletados foi baseada em Spink e Lima (2000), que propõem a compreensão dos sentidos produzidos pelos sujeitos. Entende-se sentido como uma construção social, um empreendimento coletivo, por meio do qual as pessoas, a partir das relações sociais, constroem os termos, compreendem e lidam com as situações e fenômenos a sua volta (Spink \& Medrado, 2000). Assim, a narrativa do sujeito tem sempre um caráter polifônico, já que é constituída em uma luta por significação de diferentes vozes. Assim, após a transcrição das entrevistas procurou-se "deixar aflorar os sentidos, sem encapsular os dados em categorias, classificações ou tematizações a priori” (Spink \& Lima, 2000, p. 106).

Com isso, fez-se a elaboração de quadros/mapas, que se inicia com a definição de categorias gerais que refletem os objetivos da pesquisa; em seguida, organizam-se os conteúdos a partir dessas categorias, mantendo a sequência das falas, apenas sendo deslocada para as colunas previamente definidas, em função dos objetivos da pesquisa. Esses mapas possuem o objetivo de sistematizar o processo de análise das práticas discursivas, constituem-se como um instrumento de visualização que dá subsídios ao processo de interpretação e facilitam a comunicação dos passos subjacentes a este processo.

A análise foi construída de maneira a propiciar a visualização dos sentidos produzidos pelos entrevistados, dos quais emergiam as temáticas discutidas sobre o trabalho, a empresa, o afastamento e a doença. Essas questões serão apresentas a partir de três eixos temáticos, quais sejam: o trabalho e seus sentidos; a percepção do discurso organizacional e qualidade de vida no trabalho; e, por fim, a doença, o afastamento e o retorno ao trabalho.

\section{O trabalho e seus sentidos}

A palavra trabalho, ao longo da história, vem recebendo diferentes significações. É um importante determinante da forma de organização das sociedades, sendo o meio através do qual o homem constrói o seu ambiente e a si mesmo. Hoje assistimos a transformações importantes no mundo do trabalho, porém ele conserva um lugar importante na sociedade e exerce grande influência sobre a motivação dos trabalhadores e sobre sua satisfação e sua produtividade. Segundo Codo (1997, p. 26), o trabalho pressupõe "uma relação de dupla transformação entre o homem e a natureza, geradora de significado". Corroborando, Tittoni (2008) define o trabalho como um conjunto de diversas possibilidades de articulação das fontes naturais e sociais, que possibilitam a utilização da criatividade humana para a produção de vida, relacionado com a criação, e de sua manutenção, que se vincula com a sobrevivência.

O trabalho é rico em sentido individual e social, é um meio de produção da vida de cada um ao prover subsistência, criar sentidos existenciais ou contribuir na estruturação da identidade e subjetividade. Jacques (2002) refere-se à identidade como tudo que é vivenciado 
como eu em reposta à pergunta "quem és" (p. 161), aprendido através das representações de si mesmo. Uma vez que as relações sociais ocupam lugar destacado nessa constituição, assim o trabalho e suas relações constituem também "modos de ser" (Jacques, 2002, p. 163). Já refletir sobre subjetividade ligada ao trabalho, conforme Nardi, Tittoni e Bernardes (2002), implica em pensar maneiras como as experiências do trabalho conformam modos de agir, pensar, sentir e trabalhar amarrados em dados momentos que evocam a conexão entre diferentes elementos, valores, necessidades e projetos.

Então, o sentido do trabalho varia na medida em que deriva do processo de atribuir significados que se apresentam associados às condições históricas da sociedade (Tolfo \& Piccinini, 2007). No contexto deste estudo três entrevistados produziram o sentido do trabalho como um sonho realizado:

meu sonho que sempre dizia pra eles (sobrinhos), desde guri, eu concretizei na empresa. Nós brincávamos... e fazia como se estivesse dirigindo um ônibus, o freio era um tijolo e o outro era o acelerador (E).

até que eu fui longe; me tornei motorista. Quando eu comecei meu sonho era vir pra empresa e consegui, mas daí deu esse problema. Mas se Deus quiser vai ser reversivel (D).

sempre tive sonho de fazer essa atividade que eu faço hoje, me sinto satisfeito... de pequeno eu tive esse sonho, e ele está se tornando realidade agora... Cheguei aonde eu sempre sonhei chegar um dia, ser motorista profissional mesmo... minha esposa mesmo dizia: tu nunca teve isso aí, nunca teve esses negócios, tu tá onde tu tanto queria, onde tu falava que queria voltar a trabalhar na empresa (B).

Nas três falas há uma referência ao trabalho como realização de um sonho, e em duas como os sonhos que os participantes tinham desde criança, posicionando o trabalho em um lugar de realização. Ser motorista, para esses trabalhadores, é atingir o topo de uma carreira. Percebe-se um grande valor atribuído ao trabalho por se chegar aonde sempre quis.

É importante destacar a forte importância dada à empresa ao lugar de destaque que esta ocupa na região em que está inserida. Na terceira narrativa nota-se que ser colaborador dessa organização confere status social e satisfação ao recorrer à voz da esposa para reforçar o sentido do trabalho como suporte familiar.

O trabalho tem diversos significados; é um meio de se relacionar com os outros, de se sentir parte integrante de um grupo maior, além de ser uma fonte de sustento. Quando questionados sobre o significado do trabalho, todos o associaram ao salário, de onde se retira o próprio sustento e o da família.

é que eu tiro o sustento meu e da minha família, ele é muito importante pra mim... Não tenho outra fonte de renda (B).

a uma segurança não só financeira como moral... (E).

pra mim é isso pro meu sustento é importante no caso..." (D).

Essa situação faz com que se pense na necessidade do trabalho como provedor de renda para o trabalhador e para família. O trabalho é estruturante de uma existência, pois é através dele que nos sentimos produtivos. Mas, também remete a uma necessidade biológica e física, pois é a fonte de renda. Quando o sentido do trabalho não corresponder ao significado dado pelo conteúdo efetivo da atividade previsto socialmente, isto é, quando o sentido pessoal do trabalho separa-se de sua significação é possível pensar que o trabalho será alienado. Se o sentido do trabalho atribuído pelo trabalhador que o realiza for apenas o de garantir sua sobrevivência, trabalhando só pelo salário e sem ter consciência de sua participação na produção das objetivações, haverá a cisão com o significado fixado socialmente. 
Para Nardi (2004) as formas que os indivíduos vivem, sofrem e/ou sublimam no trabalho estão intimamente associadas ao valor moral atribuído ao trabalho e à importância deste na configuração do "ideal de eu" . As falas dos entrevistados são atravessadas pela significação do trabalho associada também ao sentimento de responsabilidade por outras pessoas e de prazer por realizar um trabalho considerado importante.

É possível visualizar esse conteúdo na fala dos entrevistados:

Responsabilidade que eu sempre gostei, sempre gostei de responsabilidade (E).

...é o que eu sei fazer no caso, é o que eu gosto de fazer, só que chegou a um ponto que, não sei, explodiu, não aguentei mais, mas é o que eu gosto de fazer (D).

Para Codo (2002) a definição de trabalho é o fato de se tratar de uma atividade cuja lógica intrínseca se estrutura a partir das possibilidades e formas com que o homem controla o seu meio ambiente mediato e imediato e/ou é controlado por ele e o sentido (o significado) que o trabalho tem para esse indivíduo ou para a sociedade. Pensando o trabalho por sua dimensão social, esse faz sentido para o sujeito na medida em que é capaz de contribuir e ser útil para a sociedade. Os participantes do estudo, em suas falas sobre a percepção que têm sobre a importância do seu trabalho para a sociedade, produzem os sentidos da dimensão social que o trabalho adquire no cotidiano:

É muito importante, sem o transporte para tudo... (D).

...para o deslocamento do passageiro da sua casa ate seu ponto de trabalho. Eu me sinto satisfeito em atender todos... É importante para o desenvolvimento da cidade (B).

A dimensão social adquire maior amplitude quando o trabalhador percebe que seu trabalho não contribui apenas para seu próprio desenvolvimento, mas para a sociedade em geral. Dessa forma, é necessário que o trabalho agregue valor tanto para o trabalhador quanto para a sociedade (Tolfo \& Picinini, 2007).

Os significados do trabalho também podem ser pensados a partir de dois vieses: um da satisfação e o outro do sofrimento. Os dois andam juntos, porém um sobrepondo o outro. Para Tolfo e Picinini (2007), a construção de sentido no trabalho é possível por meio da transformação do sofrimento, gerado pela divisão das tarefas pela organização do trabalho, em prazer pela utilização das competências e liberdades individuais, considerando que o prazer no trabalho é fundamental para a manutenção da saúde. Nesse sentido, a profissão de motorista de transporte coletivo urbano envolve particularidades devido aos objetos de trabalho. Há um desgaste envolvido pelo trabalho no trânsito, com o público/passageiros e com as regras da empresa, como horários rígidos, exigências de cumprimento de itinerários, cobranças de qualidade etc.

A partir do momento em que o trabalhador percebe que seu trabalho está lhe causando sofrimento, lança mão de estratégias de controle do meio de trabalho. Para Mendes e Dias (1991), no âmbito da relação Saúde versus Trabalho, os trabalhadores buscam o controle sobre as condições e os ambientes de trabalho para torná-los mais saudáveis. Assim, quando os trabalhadores são indagados sobre o que lhes desgasta no trabalho de motorista, é percebida uma similaridade no modo de agir dos participantes na busca de uma preservação da saúde no seu cotidiano.

A primeira coisa é tu ficar surdo, procurar desligar de tudo. Só tem a pressão, desligar do que falam, do que comentam. Aqui tu tem que sentar ali e achar que tá só tu, esquecer o resto. Só ter

$2 \mathrm{O}$ termo remete aos valores em relação aos quais o indivíduo julga o sucesso de sua trajetória de vida, ou seja, aqueles que determinam o que deve ser atingido para que o sujeito possa ser feliz e pagar inconscientemente sua dívida, a qual é o que, para cada sujeito, justifica sua existência no mundo (Nardi, 2004). 
cuidado com as portas. Faz de conta que tu tá sozinho (D).

Eu procuro me distrair, não ficar matutando aquilo ali, tentando resolver o que não é pra mim. Procuro me desligar daquele momento... tem horário para cumprir, tem várias coisas que preocupam ali... Dai a gente tem que desligar um pouco se ficar matutando... (B).

Mesmo o trabalhador que já retornou às atividades de trabalho após um período de afastamento refere-se à mesma estratégia ainda utilizada por ele como mecanismo de controle das variáveis que influenciam o trabalho, buscando contornar as situações causadoras de sofrimento.

Agora eu tô aprendendo a desligar, antes eu matutava muito, logo que eu entrei na empresa, tanto é que veio esse problema do afastamento (B).

As narrativas que expressam essa estratégia de "desligar-se no trabalho" produzem sentidos de mecanização e "maquinização" do trabalho. Os enunciados soam ao ouvinte como se houvesse um "botão liga e desliga" que o trabalhador acionaria para ficar alheio a tudo que lhe traga sofrimento.

Para Ramos, Tittoni e Nardi (2008), a análise do trabalho mostra as noções de produtividade e de capacitação nas quais os trabalhadores ainda figuram como os principais elementos. Assim sendo, os trabalhadores estão em constante pressão em termos de exigência de qualificação e de atualização para o desempenho do trabalho como forma de garantia do aumento da produtividade. Portanto, ainda em relação às estratégias de proteção utilizada, é possível perceber uma transformação no comportamento do motorista no momento em que inicia o trabalho propriamente dito dentro do ônibus. Um dos entrevistados pontua duas formas de lidar com as situações a sua volta.

descontraindo a turma, sempre brincando, sempre alegre. Procuro descontrair fazendo uma brincadeira que gostem... eu descontraio, porque é um meio de tu 'desgastar', sair fora, desligar um pouco, é esse meio que tu tem. No momento em que sento atrás do volante eu sou outra pessoa... meu modo de agir no volante é um e fora do volante é outro. Eu sou sério e responsável. Não sou muito de estar mostrando os dentes... procuro não entrar muito na vida do passageiro, nem me envolver com passageiro... sentei atrás do volante, é srio, bom dia, até logo, tudo bem (B).

Dessa forma, as narrativas dos trabalhadores afirmam a realidade desgastante do trabalho de motorista. Embora o sujeito esteja entre muitas pessoas na condução de um ônibus, necessita distanciar-se dos outros e "desligar-se" de tudo para cumprir sua função. É preciso sentir-se só em um ambiente em que não está sozinho. A mobilização dessa estratégia torna-se necessária pelos objetos próprios de trabalho envolvidos na função de motorista, como o trânsito, a necessidade de atenção e concentração exigidas para a realização da atividade.

Jacques (2002) discorre que, ao transformar a natureza através do trabalho, o homem transformou suas condições de ser e estar no mundo e suas condições de adoecer e morrer. As repercussões do processo de trabalho sobre a saúde do trabalhador são, segundo Dejours (1986), citado por Jacques (2002), derivadas tanto das condições de trabalho como da organização do trabalho. Enquanto as condições de trabalho dizem respeito às condições físicas, químicas e biológicas do ambiente de trabalho, e se refletem sobre o físico do trabalhador, aquelas que dizem respeito à divisão técnica e social do trabalho, como, por exemplo, hierarquia, controle, ritmo, repercutem sobre a saúde psíquica, causando-lhe sofrimento. 


\section{A percepção do discurso da empresa e a qualidade de vida no trabalho}

Os novos problemas de saúde do trabalhador devem-se a velhas razões, mas isso não significa que não existam novas situações no mundo do trabalho que provoquem adoecimento. Alguns problemas continuam a ser observados quando há falta de sintonia entre os contextos de trabalho e as pessoas. Essa sintonia não está dada ou pronta, mas deve ser construída. Regras e limites nos ambientes de trabalho sempre existirão, pois, além da imposição pela própria natureza física, estes são balizadores que organizam a vida social. Nesse sentido, o problema não é a existência dessas regras e limitações, mas a impossibilidade de negociá-las, de modificá-las e reconstruí-las, a partir não apenas de uma lógica instrumental, mas também de uma lógica dialogada, pautada no mundo vivido (Sato, 2002).

Uma empresa é um grupo social, no qual as pessoas interagem, porque precisam ou simplesmente porque estão juntas. Relações desiguais marcadas pela hierarquia interna, relações entre iguais, colegas de trabalho submetidos às mesmas injunções, demonstram que as relações com a chefia e os colegas são importantes em termos de preservar ou prejudicar a saúde mental (Codo, 2002). Quando questionado sobre os desgastes do trabalho, um dos entrevistados associa o cotidiano de trabalho à cobrança da chefia, evidenciando uma relação que produz sofrimento.

A pressão no dia a dia, a cobrança. Pressão por parte da direção, do trânsito; se tu faz errado te cobram, mesmo tu "tando" certo, a pressão é horrivel. Eles cobram demais (D).

A narrativa do mesmo entrevistado, em outro trecho, expressa o confronto de sentidos do trabalho na organização. Ao mesmo tempo em que a empresa é caracterizada como um lugar bom, também é associada à cobrança e à ameaça.

Aqui é um lugar bom de trabalhar, mas a cobrança é forte, é pesada, tem ameaça, se tu não fizer como tem que ser, daquele jeito... (D).

Cobranças e ameaças caracterizam estratégias de disciplina que são operadas dentro das instituições com o objetivo de tornar o trabalhador mais produtivo e eficiente. A combinação dessas operações de poder com a vigilância, outra característica forte no meio do trabalho, garante o controle da força de trabalho dos trabalhadores (Foucault, 1977). Assim, podemos dizer que as relações hierárquicas estabelecem o lugar que cada um deve ocupar nas organizações, influenciando a conduta dos trabalhadores.

Uma das consequências da articulação desses dispositivos de poder é a constituição de vínculos de dependência do trabalhador com a empresa, que são regulados por gratificação e punição. Assim, o trabalhador reconhece o valor de seu trabalho quando recebe elogios. No contexto pesquisado estes derivam, muitas vezes, da constatação de que o trabalhador realizou tarefas além das correspondentes às suas atividades de trabalho. Os entrevistados ao referirem seus sentimentos de reconhecimento os associam aos elogios recebidos no ambiente organizacional:

Através de elogios, de avaliações... de desempenho... nessa relação (B).

Existe reconhecimento... é cobrado, mas também é reconhecido. Através dos elogios pela parte da fiscalização. Às vezes tu ficou até mais tarde, ou trabalhou no final de semana, daí vêm ou te fazem um elogio... isso é bom pra gente, é um incentivo, tu fica sabendo que eles reconhecem teu esforço (D).

Nesse sentido, podemos recorrer a Foucault (1977) quando se refere à sanção normalizadora como mais um princípio da disciplina. Este consiste em um sistema duplo de 
recompensa (por exemplo, a promoção) e de punição (degradação). Esta é instituída para corrigir e reduzir desvios, especialmente mediante pequenas penalidades ou gratificações. Nesse sentido, é possível perceber que as estruturas disciplinares ainda constituem formas de organização dos sistemas empresariais.

As falas dos trabalhadores são atravessadas pelo discurso organizacional quando referem como se sentem exercendo a função de motorista e como avaliam as condições de trabalho, evidenciando o caráter polifônico das narrativas. Podemos ouvir a voz da direção da empresa, dos cursos e programas organizacionais como um elemento em uma trama de significações que produz sentidos na narrativa de um trabalhador em dois momentos distintos da entrevista:

Ajudando a empresa no que ela conquistou... sempre procurei alcançar as metas e tive sucesso em $90 \%$ das vezes, em todas as metas (E).

...o discurso da direção que assim ajudaram muito a gente a ter essa paciência, esses cursos que a empresa oferece que, graças a Deus, e as outras empresas não oferecem...tudo isso eu praticava (E).

Na primeira narrativa o trabalhador assume, de fato, a posição de colaborador conforme é nomeado pela empresa ao mencionar que ajuda a empresa a alcançar as metas. $\mathrm{O}$ trabalhador é subjetivado pelo discurso organizacional e, ao se identificar com ele, é interpelado a assumir a posição de sujeito prescrita para ele. Portanto, o discurso da organização produz poderosos modos de subjetivação, tanto que, na segunda narrativa, o trabalhador recorre à voz da direção para descrever uma mudança de comportamento ao associar a aquisição de paciência aos cursos oferecidos pela empresa. Assim Morin (2001) nos diz que sentido do trabalho é fortemente influenciado pela organização do trabalho, pois esta é capaz de alterar os comportamentos de forma que os trabalhadores passem a ter atitudes positivas para com as funções que executam, com a organização e com eles mesmos.

Tendo em vista o lugar que o trabalho ocupa na vida das pessoas, a constante complexificação dos processos produtivos e sua relação com a saúde do trabalhador, o discurso qualidade de vida no trabalho (QVT) é enfatizado no contexto das organizações e fundamentam práticas voltadas para a melhoria das condições de trabalho.

Para França (2008), qualidade de vida é a percepção de bem-estar, a partir das necessidades individuais, ambiente social e econômico e expectativas de vida. No ambiente de trabalho, qualidade de vida, saúde e ergonomia estão articuladas, e é preciso ter sensibilidade para identificar os riscos ocupacionais observáveis e os implicados em cada atividade, assim como traçar estratégias para controlá-los. Sendo assim, quando nos referimos ao trabalho, França (2008) evidencia que qualidade de vida no trabalho representa hoje a necessidade de valorização das condições laborais, da definição de procedimentos da tarefa em si, o cuidado com o ambiente físico e dos bons padrões de relacionamentos.

A origem do movimento de qualidade de vida no trabalho remonta a 1950, na Inglaterra, a partir de estudos que pretendiam analisar a relação entre indivíduo, trabalho e organização. Porém, a preocupação com a qualidade de vida no trabalho, referindo-se às ações das empresas, somente apareceu nos anos 1970 nos EUA, devido à competitividade internacional e ao grande sucesso dos estilos e técnicas gerenciais dos programas de produtividade japonesa (Rodrigues, 1991).

Dessa forma, o discurso de QVT remete ao resgate da humanização das empresas, buscando incorporar algumas preferências do trabalhador nos sistemas de gestão organizacionais, trazendo um equilíbrio entre trabalho e lazer, tornando-os mais satisfatórios ao indivíduo e contribuindo para a qualidade de vida geral (Barros \& Santos, 2005; França, 2008). A empresa pesquisada desenvolve ações que visam à implementação de programas de 
qualidade cujos objetivos são voltados para a busca da melhora da qualidade de vida de seus trabalhadores. Os discursos associados à qualidade de vida atravessam as falas dos trabalhadores e os interpelam, muitas vezes, a adotar certos hábitos, regulando práticas cotidianas.

As iniciativas da empresa pesquisada fazem parte de um contexto fundado a partir de modos de produção mais flexíveis, e há por parte do trabalhador um reconhecimento das boas iniciativas da empresa, como apoio à sala de musculação e cuidados com a saúde, com a presença de um médico e uma enfermeira do trabalho. Entretanto, a narrativa a seguir também veicula a ideia de que os trabalhadores mostram resistência a aderir aos programas, associada ao medo e à inibição. O medo tradicionalmente está associado ao desconhecido. Portanto, é possível pensar que essas práticas não são familiares aos trabalhadores que mostram dificuldade de construir sentidos para incorporá-las no seu cotidiano.

Tinha enfermeira que ia lá medir a pressão... aqui na empresa eu fazia musculação, eu caminhava, pra saúde a empresa ninguém bate, para o funcionário se sentir bem. Os caras não procuram porque não querem... 70\% dos funcionários não aproveitam, eles têm não sei se é medo, o que é, eu sou desinibido eu vou lá e se tem eu faço (E).

Em outra narrativa que se refere aos programas que buscam aproximar família do trabalhador e a empresa, o trabalhador ao falar sobre sua (não) participação, nomeia-se como "estranho".

Tem vários programas, mas eu sinceramente nunca participei de nenhum... mas eu sou estranho, eu não consigo... Saem bailes, saem festas, eu só venho no fim do ano para não dizerem que não participo, mas isso nem é participar... Mas a minha família é separado da empresa, eu não sei por que, mas... mas eu sempre fui assim... (D).

A sensação de estranheza pode estar relacionada à resistência do trabalhador a aderir a uma normativa que vem se naturalizando no ambiente organizacional. Assim, os discursos circulantes da filosofia da empresa criam posições de sujeito para serem ocupadas pelos trabalhadores, produzindo o autocontrole das suas condutas. Os enunciados dos programas organizacionais também constituem as identidades dos trabalhadores ditos "normais". Assim, aqueles que não se comportam conforme a norma se reconhecem como um diferente.

A criação de práticas sociais aproximam a família do trabalhador - empresa pode ser entendida como uma ação que também tem a finalidade de exercer controle sobre o sujeito, desde que force uma articulação entre vida pessoal, social e profissional. A narrativa de outro entrevistado reforça a importância que o trabalhador atribui para a separação entre o ambiente de trabalho e o ambiente familiar.

...eu procuro fazer a minha parte, do meu horário aqui, e procuro estar mais em casa com a minha esposa, minha família. Eu sou muito caseiro. ...Eu já faço minha parte bem feita aqui bem caprichada, para poder fazer bem feita em casa também (B).

Os trabalhadores indicam que necessitam de um distanciamento do "ambiente trabalho" das outras dimensões de sua vida, Então, cabe questionar até que ponto a proposta dos programas de qualidade de vida no trabalho acabam tomando conta de todas as esferas da vida do trabalhador e produzindo efeitos contrários da proposta inicial de potencializar o bemestar e o desempenho.

Quando a empresa se faz presente em momentos com a família e em momentos de lazer retira do trabalhador o poder de escolha e decisão segundo sua vontade. A articulação dos sentidos das falas dos trabalhadores mostra que estes entendem que é preciso atender ao que a 
empresa está lhe pedindo, mesmo nos horários em que não se está trabalhando. Afinal, assim se obtém reconhecimento, assegura-se a manutenção do emprego e quem sabe até uma promoção.

A respeito dos programas de qualidade de vida, Tolfo e Picinini (2007) relatam que eles podem fazer com que o trabalhador conheça mais sobre sua atividade, possibilitando que a organização alcance a eficácia sem a preocupação de constantes reforços ao trabalhador com programas motivacionais para estimulá-lo a gerar melhor desempenho. Contudo, o alcance desses resultados está relacionado aos sentidos produzidos pelos trabalhadores para os programas.

\section{A doença, o afastamento e o retorno ao trabalho}

O sofrimento psíquico e a doença mental ocorrem quando e apenas quando afetam esferas de nossa vida que são significativas, geradoras e transformadoras de significado. Codo (2002) propõe que uma das atividades humanas em que deveríamos procurar as causas do sofrimento psíquico é o trabalho.

Nardi (2004) refere que o adoecer no trabalho, assim como a capacidade de superação dos limites impostos pela doença e da luta por melhorias nos locais de trabalho são dependentes da relação construída socialmente entre os sujeitos e o trabalho. No contexto pesquisado o trabalho e a empresa são investidos de sentidos como um lugar de realização de sonhos, refletindo diretamente no discurso do trabalhador que se reconhece como parte pertencente e fundamental para o desenvolvimento e crescimento da empresa. E irá relacionar-se proporcionalmente com o sentimento em relação à doença e ao afastamento.

Ao analisar a temática doença, perpassamos pelo território do discurso médico, que, conforme Ramos et al. (2008), quando associado ao capital, produz significados para a doença como demonstração de fraqueza e incapacidade do trabalhador, o que faz com que o trabalhador, ao se reconhecer doente, também se reconhece incapaz. Em parte os trabalhadores produzem sentidos para a doença e para afastamento através das emoções associadas à empresa e ao seu trabalho.

A relação do trabalhador com a doença é marcada pela falta de conhecimento a respeito do que se passa com ele. Saber seu diagnóstico poderia ser útil para uma maior informação e conhecimento sobre sua situação e possíveis ações que pudessem contribuir para uma melhora do quadro apresentado. Aqui não está em jogo exclusivamente um nome, mas a informação sobre si e seu adoecimento. Assim, seria possível evitar que o indivíduo se reconheça como uma sigla que não lhe traz nenhum sentido. A fala a seguir explicita a falta de conhecimento sobre seu diagnóstico associada ao uso da medicação. Chama a atenção a presença da medicalização no contexto da saúde do trabalhador.

Não sei te dizer o nome, é F alguma coisa, F 10 alguma coisa, eu vou lá no doutor e ele só me muda a medicação, já tomei vários remédios (D), como também:

Por enquanto eu acho que ele ainda não me deu nenhum diagnóstico, só me deu medicamento e um acompanhamento específico (B).

Em diferentes momentos da entrevista, as narrativas sobre a doença mental dos trabalhadores são associadas a uma descrença e desvalorização de sua existência, principalmente por esta não estar marcada na aparência ou não apresentar manifestações no corpo. Na última fala o trabalhador refere-se ao olhar do outro, que o enxerga como são, pois a doença mental nem sempre está visível ao outro. 
...eu nunca acreditei que podia ficar assim, achava besteira, que isso não ia acontecer comigo (D).

Mas nunca acreditei que existisse essa coisa de depressão, de ficar saturado com isso, mas não sei se era a hora de estourar esse estopim, eu tava bem, eu podia trabalhar (E).

Porque tu olha pra mim eu tô aparentemente são, eu não tenho nada (E).

Além da grande mistificação em torno da doença mental, há também uma dificuldade do trabalhador em reconhecer-se doente, comunicada através da expressão que médico "é coisa de outro mundo".

Olha, é que eu nunca tinha sentido isso, nunca tinham me dado esses problemas de saúde que me deu. Nunca tinha entrado nesse ramo de afastamento de trabalho. De ter que me afastar do trabalho por problema de saúde, nunca passei por isso, porque médico pra mim é coisa do outro mundo... (B).

O discurso social de incapacidade e da quase "inutilidade" atravessa as narrativas daqueles trabalhadores que não conseguem acompanhar as exigências do trabalho. Segundo Ramos et al. (2008) o não-trabalho convoca a entrada no domínio do risco de desfiliação, que pode ser sentida como um processo de fragilização e ruptura dos laços e das relações sociais conquistadas no trabalho. A produção de sentimento de abandono, ao ser perguntado sobre o apoio da família e dos amigos na situação de afastamento, está associada a esses significados sociais de desqualificação.

Eles nem me visitam mais. Só minha mãe (E).

O medo da desfiliação decorre da insegurança causada pelo risco do desemprego, a qual é potencializada pela competitividade que se vive no mundo do trabalho. Na narrativa a seguir o trabalhador projeta-se no futuro após o término do afastamento e associa esse momento ao receio de ser demitido por meio de uma analogia com uma bola nova de futebol. O trabalhador identifica-se com uma bola, que pode ser chutada, ou seja, ocupa a posição de um objeto. Portanto, os recursos linguísticos empregados comunicam a forma agressiva com que este se sente controlado pela força produtiva.

Eu acho que depois que eu terminar esse tratamento eu tô zero; é como tu pegar uma bola de futebol nova e chutar, só espero que não seja para a rua... (E).

Por outro lado o afastamento, conforme Ramos et al. (2008), pode apontar uma potencialidade como resistência, pois o "estar fora" pode mobilizar afetos silenciados pelo cotidiano de trabalho, e a partir daí inicia-se uma busca por outras atividades e até outros modos de trabalhar.

queria buscar outra profissão, fazer uma coisa mais sem tanto compromisso, mais calma, sem horário... até pela acomodação, eu sou uma pessoa muito acomodada, não quero crescer, até que eu fui longe, me tornei motorista... (D).

O rompimento com o trabalho, na perspectiva do acontecimento, pode provocar uma revisão dos modos de viver, dos sentidos do trabalho, das práticas de trabalho e das relações com o trabalho. Os modos de sujeição, o poder da norma e seus efeitos podem ser visibilizados por essa revisão, surgida a partir da experiência do afastamento. Esse sentimento de revisar gera questionamentos que são permeados pela vivência de inutilidade. Isso clarifica um ponto de tensão no qual os regimes de verdade do trabalho são tomados como referências para a experiência de si e para o auto-reconhecimento (Ramos et al., 2008). 
Jacques (2002) relata que os afastados temporariamente do trabalho cumprem uma rotina diária como se continuassem a trabalhar para que outros não percebam o rompimento do vínculo, corroborando a ideia do sistema identitário de trabalhador na identidade do eu e do trabalho como suporte privilegiado de inscrição na estrutura social. A manutenção de uma rotina durante o afastamento foi uma prática associada à experiência do afastamento de um dos entrevistados.

A minha mesma rotina, de cumprir o meu horário, cumpri as metas. Eu acordo a mesma hora de quando eu vinha trabalhar (E).

O rompimento imposto pelo adoecimento e consequentemente pelo afastamento é percebido como uma forma de ameaça a um lugar social conquistado pelo sujeito através do trabalho. Os trabalhadores sentem-se ameaçados em relação ao poder aquisitivo, às relações sociais, ao convívio com colegas e ao lugar ocupado na família. São invadidos por um sentimento de que falharam, e esse sentimento nutre-se pela fragilidade construída a partir de uma percepção de inferioridade em relação aos seus pares, por não poderem mais dar conta da sua atividade (Ramos et al., 2008). A respeito disso um entrevistado comenta:

É impressionante né, tu está bem, vê os outros trabalhando, é horrível, tem dias que tu chora bastante... Não é fácil, não sei te explicar bem, mas não é fácil, é horrivel... Não sei o que me deu, foi uma coisa de surpresa. Fiquei num tremor, num estado... minha esposa me perguntava qual o motivo pra eu estar assim, que eu tava diferente, assim (D).

Ramos et al. (2008) referem-se a uma dor psicológica ligada ao adoecimento e ao afastamento. Essa dor está relacionada ao rompimento, ao não poder mais, ao sentir-se inútil, e ao mesmo tempo ao risco de acusação de "simulação". Um entrevistado, ao significar sua experiência de afastamento, em dois momentos da entrevista, a associa a tristeza e dificuldade de adaptação e o desejo de não ser visto / reconhecido.

Muito triste, muito, porque se eu tinha, se eu tenho esse distúrbio é pior (E).

Foi muito difícil no começo, nos primeiros três meses, eu cheguei a ficar quase uma semana sem tomar banho, sem escovar os dentes, sem dormir de noite, sem sair na rua... para não ser reconhecido (E).

Assim, o retorno ao trabalho é um objetivo na vida dos afastados e na forma de refazer a imagem de um "bom" trabalhador, que seja reconhecido por sua capacidade, produtividade e desempenho. Segundo Ramos et al. (2008), o afastamento fratura uma relação construída, na qual o trabalhador atende o chamamento da demanda do trabalho, sente-se satisfeito por poder atendê-la, espera o reconhecimento do outro e, a partir dele, investe novamente.

A narrativa de um dos entrevistados, que já havia retornado a suas atividades, representa o afastamento como uma possibilidade de reflexão sobre a situação e a necessidade de um tempo para buscar uma reorganização. Ele constrói uma visão positiva do afastamento, como necessário para o restabelecimento da saúde:

Eu senti a necessidade, foi muito bom, sinceramente, por mais que eu não quisesse esse afastamento. Mas foi bom, porque eu precisava pisar um pouco no chão, descarregar um pouco, espairecer aquilo ali e tem um acompanhamento do médico e um acompanhamento de medicamento. Mas foi bom, mudou bastante do que eu andava e como eu ando (B).

Então a experiência de estar afastado, segundo esse trabalhador, pode ser entendida também como potencialidade de transformação. Esse sentido produz um novo olhar para o afastamento, ressignificando-o como necessário e importante para uma reestruturação. 


\section{Considerações finais}

É temerário propor conclusões sobre uma temática complexa como das relações entre trabalho e saúde mental (Jacques, 2002).

Este artigo buscou, a partir de um estudo de caso situado em uma realidade específica, levantar reflexões e inquietações, a respeito do tema saúde do trabalhador. Assim, buscou entender os sentidos do trabalho e do afastamento por doença mental produzidos por motoristas de transporte coletivo urbano. Portanto, este trabalho não permite possibilidades de esgotamento acerca de um tema amplo e complexo, mas propõe reflexões.

A importância atribuída ao trabalho foi significada de duas maneiras, uma através da atividade que lhe provém o sustento e, por outro lado, da função. A ocupação de motorista é investida de realizações, pois os três entrevistados referem-se ao lugar de um sonho. Além disso, a função motorista de transporte coletivo urbano confere status ao trabalhador que a reconhece como importante para a sociedade no geral.

O lugar ocupado pela empresa na região em que está inserida também confere ao trabalhador uma posição de destaque em seu grupo social e familiar. Nesse sentido, o discurso organizacional tem legitimidade e está arraigado nas falas dos entrevistados, que o tomam como sua verdade. Além desse, outras vozes, como da família, da empresa e de passageiros, se fizeram presentes nas narrativas e nos enunciados dos trabalhadores. Assim, os sentidos do trabalho e do afastamento foram produzidos a partir de uma polifonia.

Quando se pensa nos sentidos dos programas de qualidade de vida disponibilizados pela empresa surge uma série de questionamentos. Os trabalhadores entendem o significado social destes, porém eles parecem, muitas vezes, ser esvaziados de sentidos para o trabalhador. $O$ fato de não aderir aos programas de cuidado com a saúde pode sinalizar que o trabalhador não se reconhece nas propostas por estarem distante do seu universo cultural e simbólico. Portanto, questiona-se: como as organizações poderiam tornar esses programas produtores de sentido, a partir de práticas que ofereçam identificação com o trabalhador integrando seus modos de vida?

Por outro lado, quando os programas são realizados no espaço físico da empresa, e muitos deles fora do horário de trabalhado, não estariam fazendo com que a empresa ocupe uma dimensão muito grande na vida desse trabalhador? Será que a voz da empresa não está dominando outros contextos da vida do trabalhador?

A dor gerada pelo afastamento do trabalho está associada à forte vinculação desse trabalhador com o seu trabalho e com a empresa. $\mathrm{O}$ afastamento é oriundo das relações, que estão produzindo adoecimento, e a dor do afastamento é mais cruel do que a dor da própria doença. Pois perpassa por um olhar discriminatório, em que o valor do humano está dimensionado pelo que se faz.

Os sentimentos que foram referidos ao longo das entrevistas, de inutilidade, incapacidade, tristeza, pesar, fragilidade e insegurança, trazidos pela experiência de afastamento, tornam visíveis o lugar que o trabalho ocupa, não só na vida dos próprios indivíduos como, e talvez principalmente, na sociedade, no olhar do outro. Estar fora do trabalho significa ocupar uma posição que exclui e desvaloriza o sujeito. Segundo Guattari e Rolnik (2005), tudo o que é produzido pela subjetivação capitalística, ou seja, tudo o que nos chega pela linguagem, pela família, pelos equipamentos que nos rodeiam, trata-se de sistemas de conexão direta entre as grandes máquinas produtivas, as grandes máquinas de controle social e as instâncias psíquicas que definem a maneira de perceber o mundo.

Os sentimentos do afastamento são vividos de forma intensa, indicando a importância de ações organizacionais que procurem auxiliar o trabalhador no desenvolvimento de

\section{8}


estratégias de proteção, visando a uma melhor adaptação/saúde. Assim, a proposta de criação de um ambulatório, que tenha um olhar menos clínico e mais voltado para a promoção de saúde, pode ser uma intervenção fértil no ambiente das organizações. Um ambiente acolhedor, de escuta para esses trabalhadores, parte da ideia de Carreteiro (2003), citado por Ramos et al. (2008), que define o acolhimento como as condições de suporte, presentes no contexto do trabalho, que funcionam como apoio. $\mathrm{O}$ acolhimento pode funcionar como uma proteção que, ao mesmo tempo em que fornece um holding ${ }^{3}$, não cria uma limitação para o sujeito. Esse espaço poderia proporcionar ao indivíduo uma busca por novas referências, por desconstrução de sentidos, significados e concepções já arraigadas. A criação de intervenções como essa proporcionaria um ambiente coletivo, em que as pessoas poderiam construir a partir da negociação de sentidos estratégias de proteção. Com isso buscam-se inventar práticas que contemplem não só indivíduos "doentes", mas que também façam circular discursos de saúde, promovendo o bem-estar no trabalho.

Porém, como explicita Jacques (2002), qualquer ação terapêutica, através de atendimento individual e, principalmente, grupal, que possa representar uma melhora nos sintomas, terá limites enquanto inexistir uma identificação das circunstâncias de agravo à saúde e uma transformação efetiva das condições laborais. Em relação ao contexto estudado, é entendido que algumas relações com os objetos de trabalho não podem ser transformadas, como, por exemplo, o trânsito e as relações com os passageiros, mas é possível que algumas práticas institucionais possam ser ressignificadas. Para Spink e Frezza (2000), desconstrução refere-se ao trabalho necessário de reflexão que possibilita uma desfamiliarização com construções conceituais que se transformam em crenças e, como tais, colocam-se como grandes obstáculos para que outras pessoas possam ser construídas. É a criação de novas construções.

\section{Referências}

Barros, M. V. G. \& Santos, S. G. (2005). A atividade física como fator de qualidade de vida e saúde do trabalhador.. De http://www.eps.ufsc.br/ergon/revista /artigos/saray.pdf

Codo, W. (1997). Um diagnóstico do trabalho (em busca do prazer). In A. Tamayo, J. E. Borges Andrades \& W. Codo, (Orgs.), Trabalho, organizações e cultura (pp. 21-40). Rio de Janeiro: ANPEPP.

Codo, W. (2002). Um diagnóstico integrado do trabalho com ênfase em saúde mental. In M. G. Jacques \& W. Codo, (Orgs.), Saúde mental Ë trabalho: leituras (pp. 173-190) Petrópolis: Vozes.

França, A. C. L. (2008). Práticas de recursos humanos: conceitos, ferramentas e procedimentos. São Paulo: Atlas.

Foucault, M. (1977). Vigiar e punir. Petrópolis: Vozes.

Gil, A. C. (2007). Métodos e técnicas de pesquisa social. São Paulo: Atlas.

Guattati, F. \& Rolnik, S. (2005). Subjetividade e história. In F. Guattati \& S. Rolnik (Orgs.), Micropolítica: cartografias do desejo (pp. 33-148) (7

Jacques, M. G. (2002). Identidade e trabalho. In A. D. Cattani, (Org.), Dicionário crítico sobre trabalho e tecnologia (4a ed.). Petrópolis/Porto Alegre: Vozes/Editora da UFRGS.

Jacques, M. G. (2002). "Doença dos Nervos": uma expressão da relação entre saúde/doença mental. In M. G. Jacques \& W. Codo (Orgs.), Saúde mental Eु Trabalho: leituras (pp. 98-111). Petrópolis: Vozes.

Lanzana, A. \& Constanzi, R. (1999). As empresas familiares brasileiras diante do atual panorama econômico mundial. In J. Martins, (Org.), Empresas familiares brasileiras: perfil e perspectivas. São Paulo: Negócio Editora.

Lodi, J. B. (1993). A empresa familiar (4⿳亠丷a ed.). São Paulo: Pioneira.

3 Termo utilizado na perspectiva de Winnicott, referido à função de fornecer apoio. 
Mendes, R. \& Dias, E. C. (1991). Da medicina do trabalho à saúde do trabalhador. Revista de Saúde Pública, 25 (5), 341-349.

Minayo, M. C. S. (2002). Pesquisa social: teoria, método e criatividade (21를. ed.). Petrópolis: Vozes.

Morin, E. M. (2001). Os sentidos do trabalho. Revista de Administração de Empresas, 41 (3), 8-19.

Nardi, H. C. (2004). Saúde do trabalhador, subjetividade e interdisciplinaridade. In A. R. M. Crespo (Org.), Saúde do trabalhador no Rio Grande do Sul: realidade, pesquisa e interdisciplinaridade (pp. 43-64). Porto Alegre: Editora da UFRGS.

Nardi, H. C., Tittoni, J. \& Bernardes, J. S. (2002). Subjetividade e trabalho. In A. D. Cattani (Org.), Dicionário crítico sobre trabalho e tecnologia (4⿳亠丷a ed.). Petrópolis/ Porto Alegre: Vozes/ Editora da UFRGS.

Ramos, M. Z., Tittoni, J. \& Nardi, H. C. (2008). A experiência de afastamento do trabalho por adoecimento vivenciada como processo de ruptura ou continuidade nos modos de viver. Caderno de Psicologia Social do Trabalho, 11 (2), 209-221.

Rodrigues, M. V. C. (1991). Qualidade de Vida no Trabalho: evolução e análise no nível gerencial. Fortaleza: UNIFOR.

Sato, L. (2002) Saúde e controle no trabalho: feições de um antigo problema. In M. G. Jacques \& W. Codo (Orgs.), Saúde mental \& trabalho: leituras (pp. 31-49). Petrópolis: Vozes.

Spink, M. J. \& Frezza, R. M. (2000). Práticas discursivas e produção de sentidos: a perspective da Psicologia Social. In M. J. Spink (Org.), Práticas discursivas e produção de sentido no cotidiano: aproximações teóricas e metodológicas (pp. 17-39). São Paulo: Cortez.

Spink, M. J. \& Lima, H. (2000). Rigor e visibilidade: a explicitação dos passos da interpretação. In M. J. Spink (Org.), Práticas discursivas e produção de sentido no cotidiano: aproximações teóricas e metodológicas (pp. 93. 122). São Paulo: Cortez.

Spink, M. J. \& Medrado, B. (2000) Produção de sentidos no cotidiano: abordagem teórico-metodológica para análise das praticas discursivas. In M. J. Spink (Org.), Práticas discursivas e produção de sentido no cotidiano: aproximações teóricas e metodológicas (pp. 93-122). São Paulo: Cortez.

Titonni, J. (2008). Trabalho, poder e sujeição: trajetórias entre o emprego, o desemprego e os "novos" modos de trabalhar. Porto Alegre: Dom Quixote.

Tolfo, S. R. \& Picinini, V. (2007). Sentidos e significados do trabalho: explorando conceitos, variáveis e estudos empíricos brasileiros. Psicologia E Sociedade, 19 (1), 38-46.

Winkin, Y. (1998). Descer ao campo. In Y. Winkin, A nova comunicação: da teoria ao trabalho de campo (pp. 129. 145). Campinas: Papirus.

\section{Endereço para correspondência}

julia_psi_@hotmail.com, carolinebuaes@ig.com.br

Recebido em: 24/03/2010

Revisado em: 25/01/2011

Aprovado em: 08/02/2011 